\title{
Cardiovascular surgery training in Japan
}

Kazuo Tanemoto, MD, PhD, ${ }^{\mathrm{a}}$ Hitoshi Yokoyama, MD, PhD, ${ }^{\mathrm{b}}$ Yutaka Okita, MD, PhD,

Yuichi Ueda, MD, PhD, ${ }^{\mathrm{d}}$ Shinichi Takamoto, $\mathrm{MD}, \mathrm{PhD},{ }^{\mathrm{e}}$ Hitoshi Yaku, MD, PhD, ${ }^{\mathrm{f}}$ Ko Bando, MD, PhD, ${ }^{\mathrm{g}}$ and Kazuhiro Hashimoto, $\mathrm{MD}, \mathrm{PhD}^{\mathrm{h}}$

Supplemental material is available online.

$\checkmark$ Video clip is available online.

The history of cardiovascular surgery in Japan dates back to 1928 when Seo and associates first reported on surgeries for constrictive pericarditis in 3 patients, as described by Kimoto. ${ }^{1}$ Unfortunately, the advancement of cardiac surgery was completely interrupted by World War II. During the 1950s and 1960s, however, Japanese cardiovascular surgeons made significant contributions to the clinical application of hypothermia and total circulatory arrest, along with the development of techniques of cardiopulmonary bypass. $^{2-4}$

Starting in the 1970s, various innovative techniques were developed in Japan, including aortic annular enlargement by Konno and associates ${ }^{5}$; right ventricle to pulmonary artery shunt for hypoplastic left heart syndrome by Sano and associates ${ }^{6}$; and retrograde cerebral perfusion technique as an adjunct to deep hypothermic circulatory arrest by Ueda and associates. ${ }^{7}$

Japan has a population of approximately 120 million people, with $28.4 \%$ older than 65 years of age; importantly,

From the a Department of Cardiovascular Surgery, Kawasaki Medical School, Kurashiki, Japan; 'bepartment of Cardiovascular Surgery, Fukushima Medical University, Fukushima, Japan; 'Cardio-Aortic Center, Takatsuki Hospital, Osaka, Japan; ${ }^{\mathrm{d}}$ Nara General Medical Center, Nara, Japan; ${ }^{\mathrm{e}}$ Department of Health Policy and Management, Keio University School of Medicine, Tokyo, Japan; ${ }^{\mathrm{f}}$ Department of Cardiovascular Surgery, Kyoto Prefectural University School of Medicine, Kyoto, Japan; ' Department of Cardiac Surgery, The Jikei University School of Medicine, Tokyo, Japan; and ${ }^{\mathrm{h}}$ The Jikei University School of Medicine, Tokyo, Japan.

Funding: K.B. received a Japan Surgical Society Clinical Investigation Project Award in 2020 .

Received for publication May 1, 2020; revisions received Dec 1, 2020; accepted for publication Dec 8, 2020; available ahead of print Dec 26, 2020.

Address for reprints: Yutaka Okita, MD, PhD, Cardio-Aortic Center, Takatsuki General Hospital, 1-3-13, Kosobe-cho Takatsuki-City, Osaka, 569-1192, Japan (E-mail: yutakaokita@gmail.com).

J Thorac Cardiovasc Surg 2022;163:166-75

0022-5223/\$36.00

Copyright (c) 2021 by The American Association for Thoracic Surgery

https://doi.org/10.1016/j.jtcvs.2020.12.090

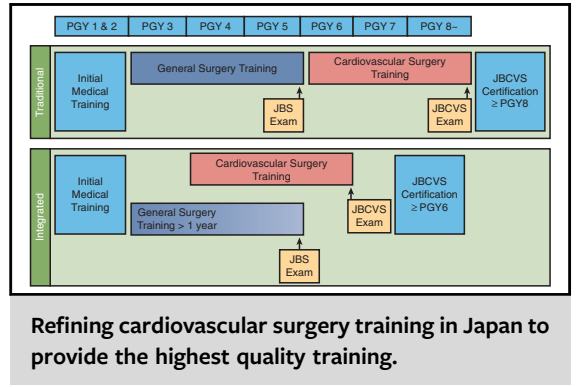

CENTRAL MESSAGE

Cardiovascular surgery training in Japan has been evolving to achieve the goal of establishing well-organized off-the-job and on-the-job training and standardized quality assessment of residents.

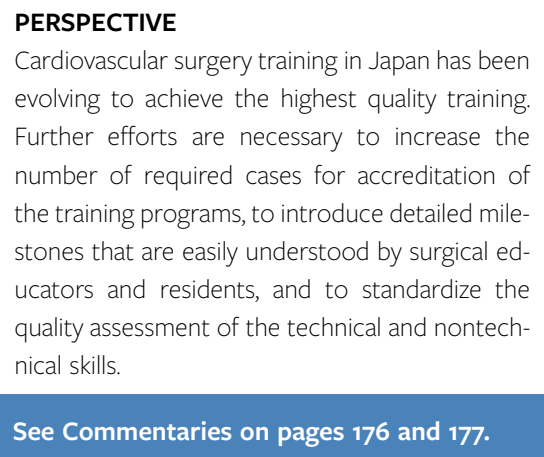

See Commentaries on pages 176 and 177.

this cohort is expected to grow and reach $39.9 \%$ in 2060 (Figure E1). ${ }^{8}$ Accordingly, the mean age of the Japanese cardiovascular surgical population increased from 67.0 years in 2007 to 70.6 years in 2018 and is expected to increase further in the near future.

The number of cardiovascular surgery cases in Japan has steadily increased from approximately 19,000 cases in 1986 to 48,000 cases in 2000 , and most recently to 69,000 cases in 2016 (Figure 1). The number of coronary artery bypass procedures peaked at 23,000 cases in 2002 and has gradually decreased since then, whereas steady growth has been observed in the number of valve and aortic 


\section{Abbreviations and Acronyms \\ ABTS = American Board of Thoracic Surgery \\ JATS = Japanese Association for Thoracic Surgery \\ JBCVS $=$ Japanese Board of Cardiovascular Surgery \\ JBS = Japanese Board of Surgery \\ JCVSD = Japan Cardiovascular Surgery Database \\ JSCVS $=$ Japanese Society for Cardiovascular Surgery \\ JSS = Japan Surgical Society \\ JSVS = Japanese Society of Vascular Surgery \\ TAVR $=$ transcatheter aortic valve replacement}

surgeries. The number of congenital heart surgeries has slightly decreased over the past 10 years (Figure 1). ${ }^{9}$

There are 2 major cardiothoracic and cardiovascular societies in Japan: the Japanese Association for Thoracic Surgery (JATS) and the Japanese Society for Cardiovascular Surgery (JSCVS). Established in 1948, the JATS has been the driving force for innovation, scholarship, and education of cardiothoracic surgeons, as well as serving as the monitoring board of annual cardiothoracic surgery procedures and their outcomes. ${ }^{10}$

The JSCVS, founded in 1972, is an academic association that serves the needs of its members and of society as a whole. The JSCVS has collaborated with the JATS and the Japanese Society for Vascular Surgery (JSVS) in creating and promoting the Japanese Board of Cardiovascular Surgery (JBCVS) since 2002. For the last 8 years, the Council of the JSCVS has invited its members aged less than 40 years to present their opinions to the Council regarding educational policies, including quality assurance, improvement of their training system, and time frame of their training period.

Supported by the JSCVS, JATS, and JSVS, the Japan Cardiovascular Surgery Database (JCVSD) was initiated in 2000. The US Society of Thoracic Surgeons National Database content was translated into Japanese, ensuring that the parameters were consistent with those used in the Society of Thoracic Surgeons database to permit comparisons of data between both countries in the future. ${ }^{11}$ Data could be registered on-line with the support of the University Hospital Medical Information Network Center in Japan. In 2012, the JBCVS decided to use the data registered in the JCVSD for the JBCVS board certification or recertification process. In this system, all applicants must register their cases in the JCVSD, and the program directors must confirm the accuracy of the data from their own institutions. Using this system, applicants can easily download the number and category of cases, information necessary for board certification or recertification. With these changes, almost all of cardiovascular surgery cases in Japan have been registered in the JCVSD since 2013. The total numbers of registered adult and congenital data entries in the JCVSD until the end of 2019 are shown in Figures E2 and E3 and Table E1.

\section{PREREQUISITE TRAINING}

All surgical trainees in Japan enter medical school after graduating from high school and are required to complete a 6-year medical school program. During the 2 to 3 months surgical rotation of the last 3 years of medical school, they are allowed to examine patients during rounds and scrub in the operating room under the direction of staff surgeons. However, they are not permitted to perform invasive procedures, focusing instead on simulator-based training.

Before entering any subspecialty surgical training in Japan, candidates must complete an initial 2-year clinical internship, which comprises the major fields of medicine including surgery, psychiatry, and obstetrics and gynecology. Unlike the North American and European systems, thoracic surgery residency is separate from that of cardiovascular surgery in Japan.

Until 2019, all candidates seeking cardiovascular surgery training were required to register as a general surgery resident and complete at least a 3-year course of general surgery and accumulate at least 350 cases (120 cases as operating surgeon) before entering cardiovascular surgery training (Figure 2). Moreover, residents in cardiovascular surgery are required to earn the Japanese Board of Surgery (JBS) Certificate before completing cardiovascular surgery training and taking the JBCVS exam. Unlike the United States, there is no independent organization like the American Board of Surgery in Japan. Instead, the JBS, under the auspices of the JSS, has been responsible for every aspect of general surgery training, including preparation of the curriculum, conducting written and oral examinations, board certification and renewal, and certification of surgical educators. In contrast, the JBCVS, endorsed by the JATS, JSCVS, and JSVS, was established as an independent organization in 2002 to assume the same role of the JBS in every aspect of cardiovascular surgery training and quality control of training programs and surgical educators. The JBCVS is financially maintained through the fees of new and renewal applications, as well as through the fees for certification of training programs. Neither these cardiovascular surgery societies nor the Japanese government plays a role in this process.

Unlike the systems in the United States, ${ }^{12}$ Canada, ${ }^{13}$ and the United Kingdom, ${ }^{14}$ there is no national residency review committee. Instead, the JBCVS monitors the quality of each program based on the requirements for the training program (Table E2). Furthermore, the members of the JBCVS perform audits of training programs, especially those with 


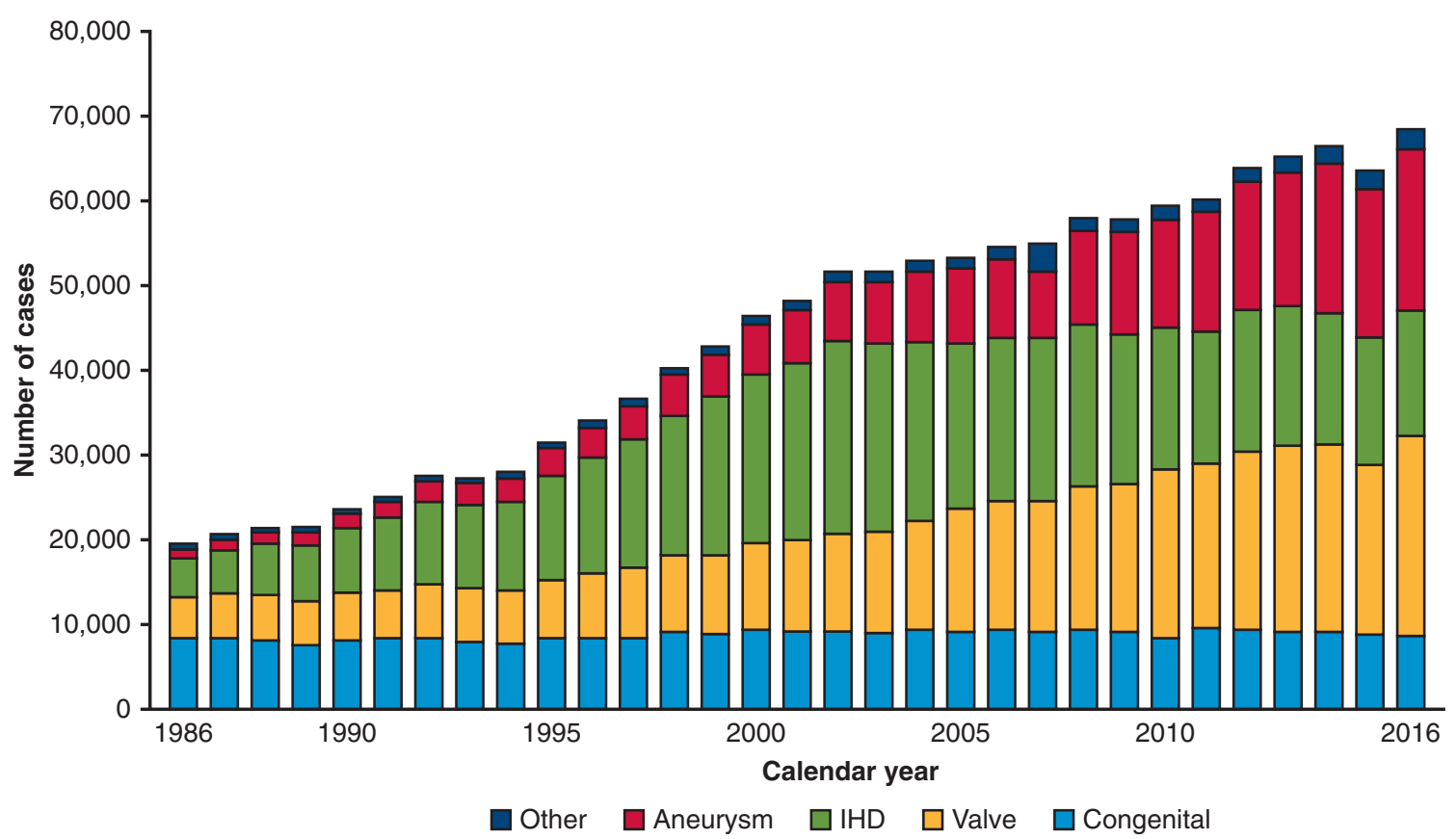

FIGURE 1. Trends of cardiovascular cases in Japan. IHD, Ischemic heart disease.

poor surgical outcomes or low numbers of applicant cases. The minimum training period in cardiovascular residency is 3 years; however, residents usually continue their training for 4 to 8 years to fulfill the requirements for application for the JBCVS board exam (Tables 1, 2, and E3, and Figure 2) and to earn 500 points of surgical experiences (Tables 3 and E3) because the majority of training programs involve 100 to 250 cases per year. The length of the training period depends primarily on the case volumes of the training program, and a few residents who are fortunate enough to train in high-volume programs can reach 500 points of surgical experiences in 3 years. Therefore, the number of residency graduates varies each year because the number of candidates for the JBCVS who fulfill the stated requirements changes from year to year (Tables 1-3). For example, graduates in the last 4 years were 183 in 2016, 176 in 2017, 156 in 2018, and 133 in 2019. The passing rate for the JBCVS written exam

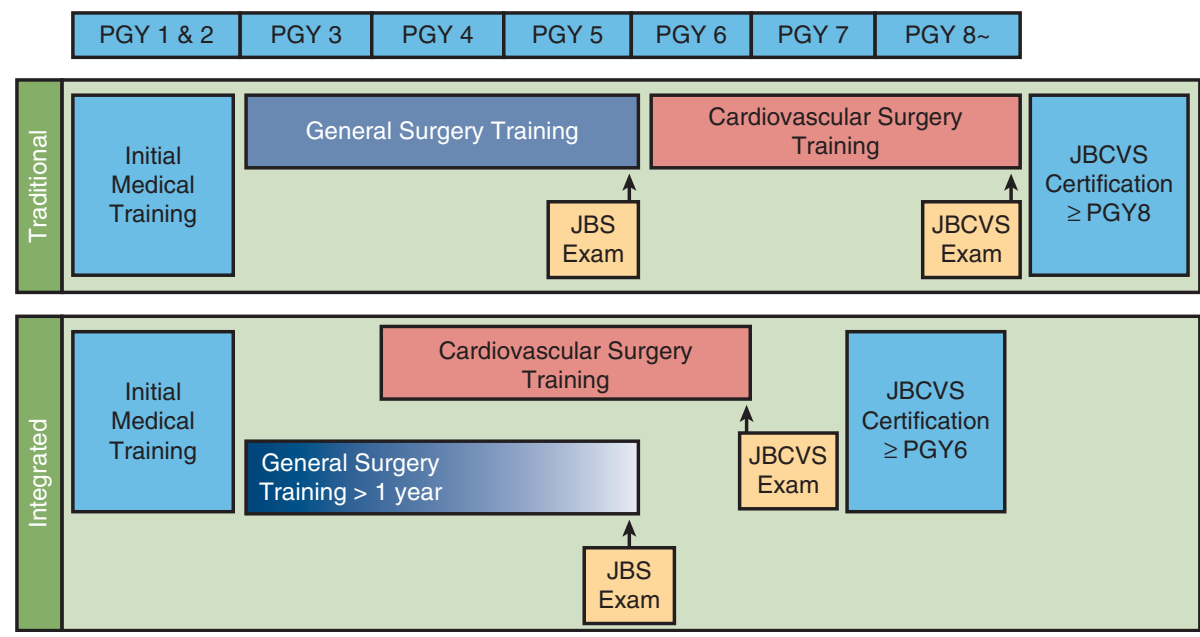

FIGURE 2. Traditional and integrated cardiovascular surgery training. All candidates seeking cardiovascular surgery training are required to register as a general surgery resident and complete at least a 3-year course of general surgery training. Residents in cardiovascular surgery are required to earn a JBS Certificate before completing cardiovascular surgery training and taking the JBCVS exam. The minimum training period in cardiovascular residency is 3 years. PGY, Postgraduate year; JBS, Japanese Board of Surgery; JBCVS, Japanese Board of Cardiovascular Surgery. 
TABLE 1. Training points depend on the procedure classification and trainee role in surgery

\begin{tabular}{llcl}
\hline & \multicolumn{3}{c}{ Procedure classification } \\
\cline { 2 - 4 } & A & B & C \\
\hline Surgeon & 3 & 4 & 5 \\
First assistant & 1.5 & 2 & 2.5 \\
Second assistant & 0.3 & 0.4 & 0.5 \\
\hline
\end{tabular}

Operation score is as per table. The surgeon is the one who actually performs the main part of the operation specified in the name of the operation. Fraudulent applications will be punished. Surgeon and instructing assistant shall fill in the operation record. In principle, 2 surgeons cannot list their names in the surgeon column.

ranged from $77 \%$ to $87 \%$ during the last 5 years; there is no JBCVS oral exam. During residency, there is no in-service exam; the trainees learn though the Self-Education, Self-Assessment in Cardiovascular Surgery, which is equivalent to the SESATS in the United States.

Unlike the American Board of Thoracic Surgery (ABTS) board certification system, the JBCVS does not set limitations on the number of attempts. Instead, candidates who fail the exam work as nonindependent surgeons, and the length of the additional training period is primarily determined by program directors. A surgeon trained outside of Japan can apply for the board examination if the program director of his/her training institution provides a letter of certification indicating that the applicant has reached the surgical experience thresholds listed in Tables 1 to 3 . However, the applicant still needs to attend JATS, JSCVS, or JSVS meetings, be present at those meetings, and to participate in a postgraduate course, as well as in the patient safety courses listed in Table 3.
Because our proposed training system only requires a Japanese medical license and completion of a 2-year internship, every candidate can apply for the JBCVS-certified training program even in the middle of his/her general surgery training period postgraduate year 3 to 5 for traditional training system (Figure 2). To recruit the best and brightest candidates from medical schools, the importance of reducing the training period while maintaining the quality of the training program was recognized. An integrated training system by overlapping general surgery and cardiovascular surgery training to lessen the total training period (Figure 2) was thus initiated in 2019. Candidates of new integrated cardiovascular training system are selected by the second year of (postgraduate year 2) their internship. The first graduates of the integrated training system will complete their training as early as 2022. To ensure optimal education, it is important to increase the number of required cases for accreditation of the training program, introduce detailed milestones that are easily understood by both surgical educators and residents, and establish an effective off-thejob training system that translates into better surgical techniques in the operating room.

\section{CARDIOVASCULAR SURGERY TRAINING PROGRAM OVERVIEW}

The Cardiovascular Surgery Training Program in Japan is divided into 2 categories based on the annual minimum number of cases (core training program: 100 cases; satellite training program: 50 cases) (Table E2). The program directors are required to maintain a high level of quality of training in each institution, which is accredited by the

TABLE 2. Classification of procedures in the training for the Japanese Board of Cardiovascular Surgery (typical cases in categories A, B, and C)

\begin{tabular}{llll}
\hline \multicolumn{1}{c}{ A } & & B & C \\
\hline Congenital & PDA & B-T shunt & TOF \\
& ASD & CoA & TGA \\
PA banding & VSD & Mitral valve plasty & Double valve surgery \\
TAP & & Aortic valve replacement & Multiple-vessel CABG \\
Coronary & & Mitral valve replacement & Replacement of aortic arch \\
Aorta & & Single-vessel CABG & \\
& & Replacement of ascending aorta & Distal artery bypass \\
Artery & Replacement of abdominal aorta & Stent grafting & Vena cava surgery \\
\hline Vein & Thrombectomy & Axillo-femoral bypass & \\
\hline Others & F-F bypass & Femoro-popliteal bypass & \\
\hline
\end{tabular}

Typical cases in categories A, B, and C are shown. Category A includes fundamental cases primarily performed by the first-year residents of cardiovascular surgery training. Category B includes routine cases typical for the second and third years of the residency. Category C represents the most advanced cases, usually performed by third-year residents or junior staff surgeons under appropriate supervision of senior staff surgeons. Complete lists of category A, B, and C cases are shown in Table E2. PDA, Patent ductus arteriosus; $A S D$, atrial septal defect; $P A$, pulmonary artery; $B-T$, Blalock-Taussig; CoA, coarctation of aorta; VSD, ventricular septal defect; TOF, tetralogy of Fallot; TGA, transposition of great arteries; $T A P$, tricuspid annuloplasty; $C A B G$, coronary artery bypass grafting; $P T A$, percutaneous transluminal angioplasty; $F-F$, femoro-femoral. 
TABLE 3. Requirements for board certification

1. $\geq 50$ cases of cardiovascular surgery as a surgeon

2. $\geq 50$ cases of cardiovascular surgery as the first surgeon

3. $\geq 3$ attendances at annual surgical meetings including the JATS, JSCVS, JSVS, or JSS

4. $\geq 3$ attendances in postgraduate courses sponsored by the JATS, JSCVS, JSVS, or JSS

5. $\geq 2$ attendances in medical and patient safety courses sponsored by the JATS, JSCVS, JSVS, or JSS

6. $\geq 3$ oral presentations at major national or international meetings

7. $\geq 3$ publications in peer-reviewed journals in a relevant field including one as a primary author

8. Minimum of $30 \mathrm{~h}$ off-the-job training

JATS, Japanese Association for Thoracic Surgery; JSCVS, Japanese Society for Cardiovascular Surgry; JSVS, Japanese Society for Vascular Surgery; JSS, Japan Surgical Society.

JBCVS. Other requirements for a qualified training program are listed in Table E2. As of August 2019, there were 422 core training programs and 120 satellite training programs. Definitions and requirements of core and satellite programs are shown in Table E2. Most cardiovascular surgery residents do not remain in 1 core hospital, but rather rotate through various core and satellite hospitals to gain experience in different types of surgery, including adult and congenital cardiac surgery, abdominal and peripheral vascular surgery, open and endovascular aortic surgery, transcatheter aortic valve replacement (TAVR), and mechanical circulatory support (Figure 3). Because of the rotation system, each resident is not assigned to 1 mentor. However, program directors of core and satellite programs regularly hold meetings and communicate effectively with one another to follow each resident's operative experience, technical proficiency, nontechnical skills, and academic productivity. Unlike the North American and European systems, there are no current limits on work hours. However, in 2023 , work hours will be restricted by limiting the total hours of overtime work to 1860 hours per year. The total number of work hours per week will thus approximate the 80-hour restriction that exists in North America.

\section{Required Surgical Experience}

The JBCVS has set criteria for the minimum surgical experience required before applying for board examination. Each cardiovascular procedure is classified into 1 of 3 categories (categories A, B, and C) depending on its difficulty and complexity (Tables 1, 2 and, E3). The range of cardiovascular procedures includes congenital, valvular, coronary, aorta, artery, vein, and intravascular procedures (Table E3). Although TAVR is ranked as a category B for $\mathrm{TF}$ approach and a category $\mathrm{C}$ for $\mathrm{TA}$ approach, rotation into a catheter laboratory is not mandatory in the current curriculum. Because more than $90 \%$ of TAVR cases are performed using the transfemoral approach and only a few cases are done using the transapical or transaortic approach, it is rare for cardiovascular surgeons to play a major role in TAVR procedures.

The trainees can acquire points depending on their role in each procedure (Table 1). For example, a trainee who performs an aortic valve replacement as the operating surgeon is awarded 4 points. The trainees must earn a total of 500 points before applying for the JBCVS examination (Tables 1-3). In addition, they must perform at least 50 procedures as the operating surgeon and at least 50 cases as the first assistant (Table 3). Attending surgeons and program directors make decisions as to whether a resident can register a case as "the surgeon" or the "first assistant." Although the minimum required number of cases for JBCVS application is lower than that of the ABTS, there

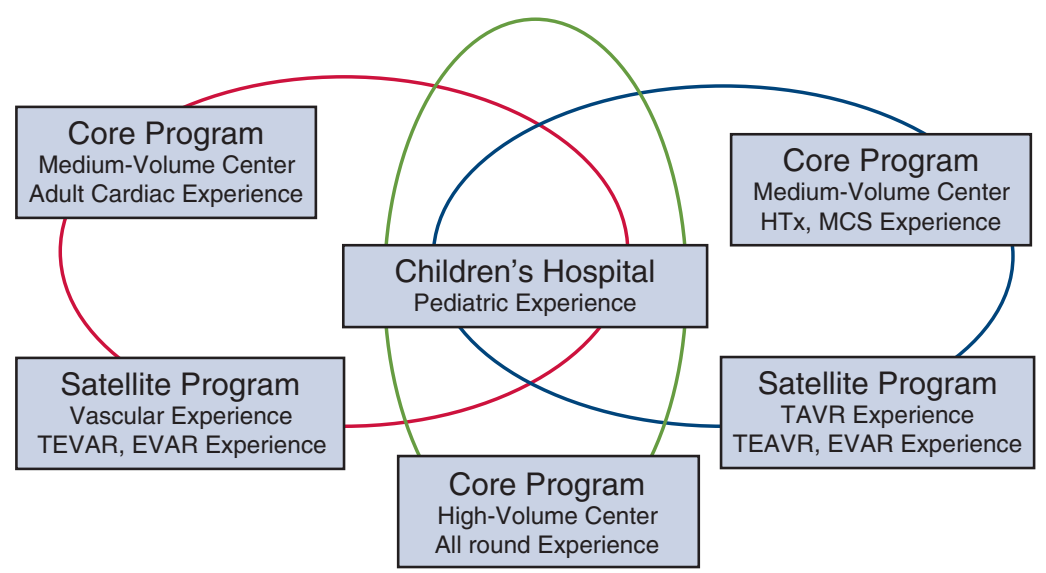

FIGURE 3. Training program groups. Core and satellite hospitals, and children's hospitals form training groups to provide residents sufficient experience in different types of cardiovascular surgery, including adult and congenital cardiac surgery, abdominal and peripheral vascular surgery, open and endovascular aortic replacement for both thoracic and abdominal arteries, TAVR, and mechanical circulatory support. TEVAR, Thoracic endovascular aortic repair; EVAR, endovascular aortic repair; HTx, heart transplantation; $M C S$, mechanical circulatory support; TAVR, transcatheter aortic valve replacement. 
is a tremendous variety in the total number of cases. The median number of indexed cases as a primary surgeon of recent applicants was between 170 and 190 cases in the last 3 years. Of those, $70 \%$ of JBCVS applicants had 100 cases, $30 \%$ had more than 250 cases, and $12 \%$ had more than 500 cases. No trainees are allowed to operate independently before obtaining JBCVS board certification. Because young graduating surgeons who pass the JBCVS board may not be sufficiently qualified to perform complex cases as an independent surgeon when they first pass the board, they remain in their own program as clinical instructors or pursue a fellowship and accumulate further surgical experience under the direction of senior staff surgeons. The chief of a training program may hire them as assistant professors or junior partners or recommend them to other programs when they are ready to operate independently. In that way, quality of surgical outcomes in each program are maintained while junior staff surgeons gain enough experiences to confidently perform complex cases independently.

Unlike the systems of the United States, ${ }^{12}$ Canada,${ }^{13}$ New Zealand, Australia, ${ }^{15}$ and other European countries, ${ }^{14,16}$ approximately $100 \%$ of young graduating surgeons stay in their programs or seek fellowships in other institutions and are paid by fixed salary. There are few private practice hospitals in Japan, and only a handful of senior surgeons work in such an environment. Although the majority of JBCVS board-certified surgeons stay in Japan, currently 40 Japanese surgeons work as attending physicians in the United States, 1 in Canada, and 5 in Germany.

Requirements for JBCVS board certification renewal, which occurs every 5 years, are shown in Table E4. Currently, approximately $10 \%$ of cardiovascular surgeons cannot renew their certification because of an insufficient number of required surgical cases during the previous 5 years (Figure 4). The pyramidal structure of cardiovascular surgery practice in our country has changed over the last 5 years. The JBCVS has been encouraging senior surgeons to become teaching assistants by doubling the points for each teaching case. For example, if senior surgeons operate as the primary surgeon on a category $\mathrm{C}$ case, they earn 1 case, but if they assist on a category $\mathrm{C}$ case as a teaching assistant, they earn 2 cases. (Table 1). By doing so, senior surgeons can easily renew their board certification by participating in surgeries as teaching assistants.

Trainees with previous procedural experience in cardiovascular surgery (ie, during their general surgery training) can receive points for those procedures to be applied toward their JBCVS application. Depending on the trainee's progress, the duration of the training may be extended (Figure 2). The JBCVS favors competencebased rather than time-based training; thus, trainees cannot apply for JBCVS certification until they fulfill all training requirements determined by the JBCVS (Tables 1-3 and
E3). Because there are no predetermined residency periods, some residents have to stay several more years to complete all the requirements before application.

\section{Courses and Simulations}

The JATS, JSCVS, and JSVS provide postgraduate seminars on topics ranging from basic surgical techniques in adult, congenital, and vascular surgery, to tips and pitfalls in advanced cardiovascular surgery. The trainees have to attend 3 postgraduate seminars by the end of their training (Table 3). These academic organizations also provide seminars on patient safety and professionalism at each annual meeting. The trainees must attend 2 of these seminars before applying for the JBCVS exam (Table 3 ).

In 2017, the JBCVS announced that 30 hours of simulator-based skill training are mandatory to apply for board examination. The JATS, JSCVS, and JSVS provide several hands-on seminars using synthetic models or animal organs for coronary artery bypass grafting, aortic valve replacement, mitral valve replacement/repair, peripheral artery bypass, and stent grafting. In 2018, the JBCVS, with the support of the 3 academic societies (JSCVS, JATS, and JSVS), published a textbook focused on off-the-job training that describes techniques in simulator-based training and includes critical case scenarios and checklists for the trainee and surgeon-educator. ${ }^{17}$ In this textbook, off-the-job training is defined as supervised practice outside of the clinical setting, such as simulator-based skill training, critical case studies, and teamwork exercises using a simulated operating system. ${ }^{17}$ The reasons for increased simulator-based learning and out-of-operating room training include the following: (1) opportunities for trainees to be the operating surgeon have decreased because of increasing numbers of technically difficult, minimally invasive procedures, such as beating heart surgery, small-incision surgery, and endoscopic surgery; (2) because of economic realities, shortened operative times are preferable, and this reduces the amount of time that can be used to teach in the operating room; (3) there is growing social concern that it is ethically unacceptable to consider the operating room as a training space; and (4) there is pressure to shorten the total training period because the length of the current paradigm negatively affects the recruitment of the best and brightest medical students into cardiovascular surgery.

\section{Trainee Responsibilities}

The JBCVS defines goals for the knowledge, surgical skills, and mindset the trainees should aim for in each training stage (Table 4). Throughout their training period, all residents are required to regularly participate in mortality and morbidity conferences and discuss both attending surgeons' and their indexed cases. Each program 


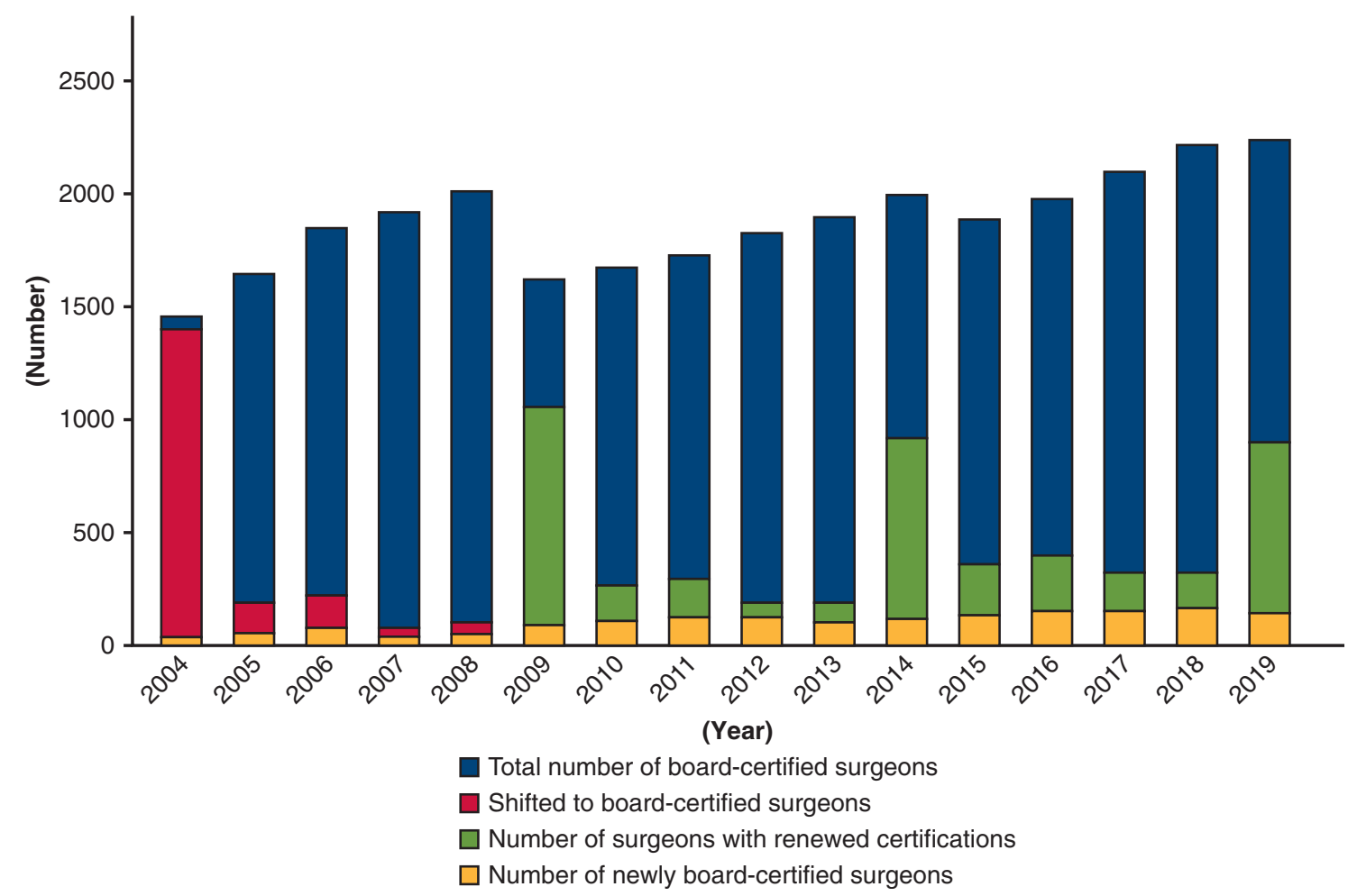

FIGURE 4. Number of board-certified cardiovascular surgeons. Green bars indicate the numbers of surgeons automatically shifted from certification by the Japanese Association for Thoracic Surgery to certification by the JBCVS.

holds teaching conferences and periodically has surgical rounds by invited guest speakers.

Curriculum prepared by the JBCVS is not as detailed as that of the ABTS Cardiothoracic Surgery Training
Milestones in the United States (Table 4). Nevertheless, the majority of institutions in Japan have a journal club and residents are required to present and discuss papers in each category of cardiovascular surgery. Moreover, all the

\section{TABLE 4. Milestones of cardiovascular training for Japanese Board of Cardiovascular Surgery certification}

\section{First stage (1-2 y)}

1. To understand surgical anatomy, pathophysiology, and pathology, which are required in clinical practice for the treatment of cardiovascular diseases.

2. To acquire knowledge of etiology, pathophysiology, and epidemiology, and learn methods for the diagnosis of cardiovascular diseases and be able to propose a treatment strategy for them.

3. To gain the ability to manage patients with cardiovascular disease in an emergency situation.

4. To perform perioperative management and basic surgical procedures including opening and closing the chest, cannulation for cardiopulmonary bypass, proper weaning from cardiopulmonary bypass, harvesting of saphenous vein grafts, closure of atrial septal defects, and peripheral vascular bypass surgery and cases listed in Category A.

5. To perform team-based medical practice and consultation with a faculty member at the appropriate time.

6. To attend scientific meetings related to cardiovascular surgery and present case reports at local cardiovascular meetings.

II. Second stage (1-2 y)

1. To perform more advanced surgical procedures including aortic valve replacement for aortic regurgitation, single coronary artery bypass or proximal anastomosis of CABG and other procedures listed in Category B.

2. To obtain proper informed consent from patients and their representatives.

3. To attend national scientific meetings related to cardiovascular surgery and present case reports or clinical studies at local or national meetings.

III. Third stage (1-2 y)

1. To perform surgical procedures, such as aortic valve replacement for severe aortic stenosis, simple CABG, and others listed in Categories B and C under the direction of surgical educators.

2. Encouraged to perform collaborative research in a basic science department or research institution.

3. Encouraged to participate in clinical research or clinical trials. Trainees are eligible for application to the JBCVS.

$C A B G$, Coronary artery bypass grafting; JBCVS, Japanese Board of Cardiovascular Surgery. 


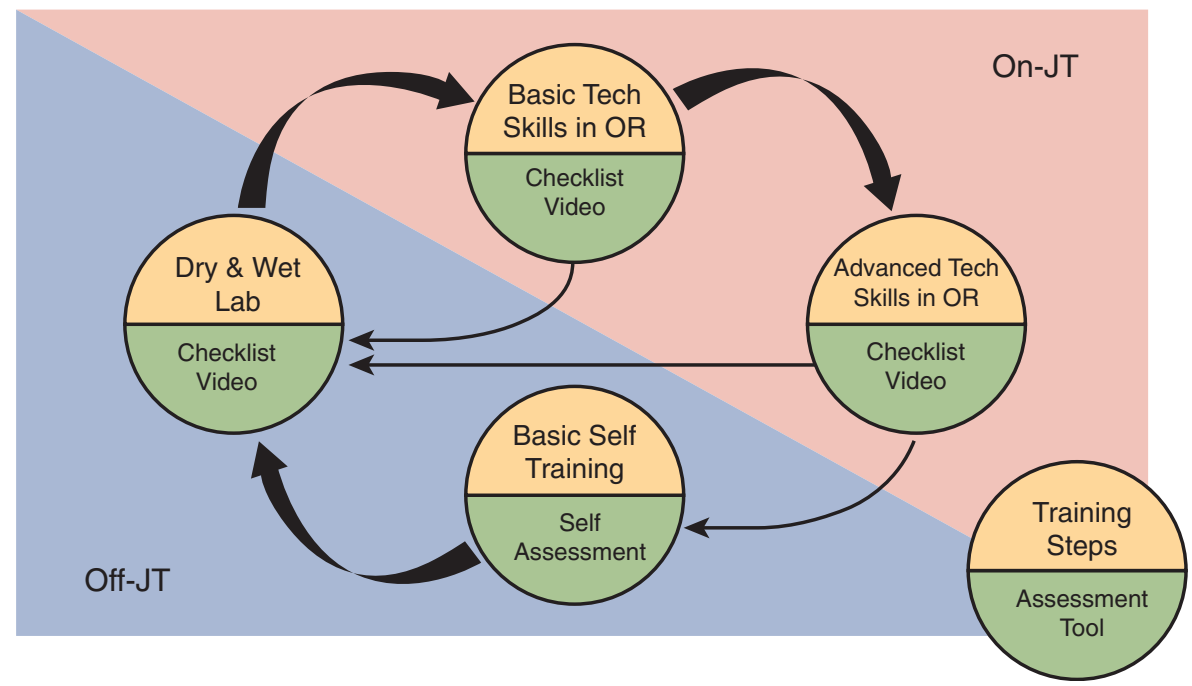

FIGURE 5. Effective training circle. Except for basic self-training, objective quality assessment of surgical techniques by both residents and staff surgeons can be performed using checklist and video reviewing. Feedback of these outcomes from staff-surgeon to resident and experience in on-the-job training to off-the-job training are essential to maximize the effect of these training circles (modified from Figure 1 of Reference 18). Lab, Laboratory; OFF-JT, off-thejob training; $O R$, operating room; $O N-J T$, on-the-job training.

residents are required to attend postgraduate courses offered at the JATS, JSCVS, and JSVS annual meetings, which is mandated by the JBCVS.

\section{ASSESSMENT}

\section{Technical Proficiency Assessment}

Technical proficiency in the operating room is measured by attending surgeons and discussed with residents during debriefing conferences usually held the morning after a surgery. Near misses and unexpected events, as well as unplanned procedures, are shared with peer residents and other staff members. Detailed technical performance of junior residents is primarily evaluated by off-the-job training using simulators, while assessment of surgical performance of senior residents is shifted toward on-thejob training in the operating room without disturbing the flow of the surgery. ${ }^{18}$

\section{Formative Evaluation}

As a way to provide feedback to specialized training programs, the JBCVS and JCVSD monitor the training progress of the trainees annually and audits those institutions with suboptimal surgical outcomes, in which case clinical input by the JBCVS and JCVSD is required. ${ }^{19}$ The JBCVS and JCVSD provide guidance and support for quality improvements in the training system, as well as surgical results. In addition, trainers are required to learn methods for providing appropriate feedback to trainees at faculty development courses, usually held during the annual meetings of the JSS, and the 3 surgical societies (JATS, JSCVS, and JSVS) sponsored by the JBCVS.

\section{All-Inclusive Evaluation}

Program directors of core institutions are responsible for confirming that their trainees have officially fulfilled the required curriculum by assessing their knowledge of the surgical approach, pathophysiology, preoperative and

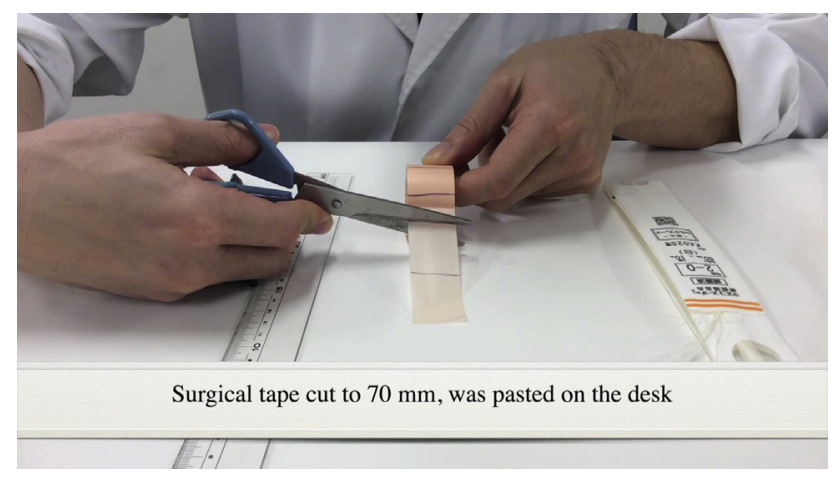

VIDEO 1. Quantitative and objective structured assessment of technical skill for slip knotting. 3M Surgical Tape (3M, Maplewood, Minn), cut to $70 \mathrm{~mm}$, is pasted on a desk surface. Next, a 2-0 or 5-0 silk thread is placed at the center of the tape horizontally, and another 35-mm length of tape is stuck on the first tape. The participants are then instructed to press the tape onto the desk as firmly as they can. As the silk thread starts to slip between the pieces of tape, the examinees slide the silk thread horizontally several times before the examination starts, without peeling off the tape. Ten knots are made tightly and slid down to the tape, taking care not to peel off the tape. The time to complete $10 \mathrm{knots}$, the peeled distance of the tape, and the vertical distance between the tape and the knot (loosened distance) are measured (Watanabe S, Kitagawa T, Tachibana K, Kurosawa H, Chiba K, Ito J, et al. Gen Thorac Cardiovasc Surg. 2020;68:557-564). Video available at: https://www.jtcvs.org/article/S0022-5223(20)33444-9/ fulltext. 


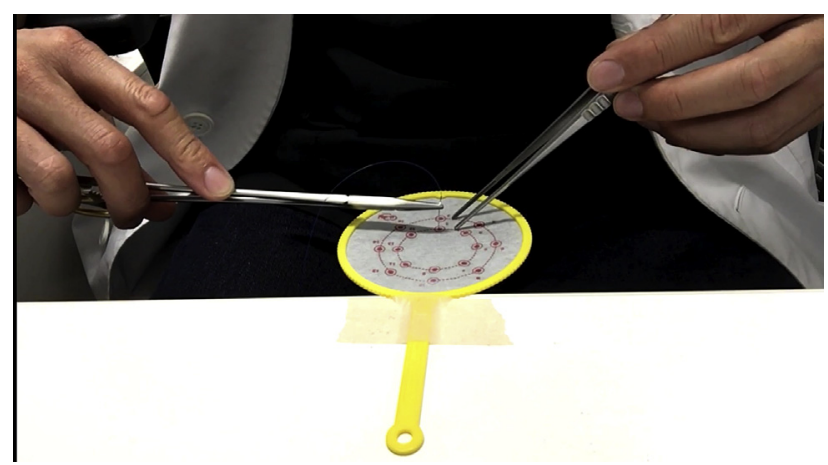

VIDEO 2. Accurate handling of needle holder. A goldfish scooper tool made of thin Japanese paper is prepared with 16 target points placed in a concentric fashion. Accurate handling of forehand and backhand needle holder along the curvature of needles in 360 degrees is tested by the distance from targets without tearing the paper. Time required for completion of the 16 target sutures is also measured. Goldfish scooping (kingyo sukui) is a traditional Japanese game in which a player scoops goldfish with a special scooper made of thin Japanese paper. This game started in the late Edo period, around 1810. Since then, the game has become popular among children, and it is usually held during summer festivals. The game is played as follows: A player scoops goldfish from a pool with a paper scooper called a "poi" and puts them into a bowl with the poi. This game requires care and speed as the poi can tear easily. The game is over when the poi is completely broken or incapable of scooping properly. Even if one part of the poi is torn, the player can continue the game with the remaining part (JATS, JSCVS, and JSV, eds. Cardiovascular Surgery Off-The-Job Training Textbook. Endorsed by JBCVS. Tokyo, Japan: Nankodo; 2018). Video available at: https://www.jtcvs.org/article/ S0022-5223(20)33444-9/fulltext.

postoperative patient care, proficiency in surgical procedures, off-the-job training experience, participation at annual meetings, and completion of postgraduate courses. Program directors also evaluate the trainees' nontechnical skills, which include leadership, professionalism, integrity, and teamwork.

\section{CHALLENGES}

Although the requirements for board certification and renewal are well established, major challenges remain in developing an ideal cardiovascular surgical training system. First, similar to the certification procedure of the ABTS, candidates for JBCVS certification are required to complete a certain number of procedures in various areas with the program director's acknowledgment before taking a written examination. In other words, there is currently no objective (or less subjective) measure to assess the candidate's technical proficiency. ${ }^{18}$ Thus, our assessment system lags those in other high-stakes professions, such as the aviation industry. ${ }^{20}$ Recently, we initiated a study to standardize the quality assessment of basic surgical techniques, including opening and closing the chest, harvesting the saphenous vein and internal thoracic artery, and instituting

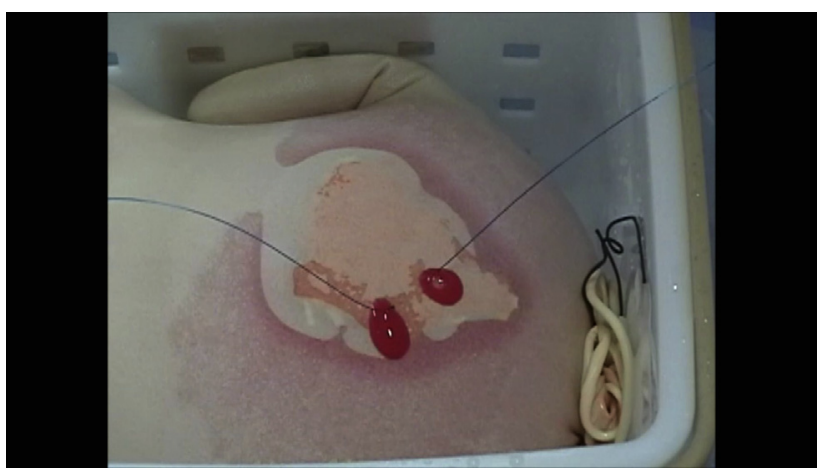

VIDEO 3. Convenient training method for aortic cannulation using 2 gloves and citrus peel. For young cardiovascular surgeons, aortic cannulation is a stressful procedure. Poor cannulation technique may lead to massive hemorrhage or other catastrophic complications. Furthermore, difficulties in performing purse-string sutures and insertion of cannula may remain problematic for surgeons for years. This video introduces a training method that provides a convenient simulation of the actual procedure. After expanding 2 surgical gloves by placing them on a hand and then removing them, a piece of mandarin orange peel is inserted between the gloves. The inner glove is filled with water, and the mouths of 2 inflated gloves are securely tied with a strong ligature. Then this "glove balloon" is set inside a container to stabilize it. Purse-string sutures are stitched through the orange peel. After the center of the purse string is incised with a number 11 blade, a cannula is introduced. Because water spills during the simulation, this should be carried out in a sink. The container is set in a sink, and purse-string sutures are stitched into the orange peel. When the needle penetrates deeper than the inside of the peel, the inner glove is perforated and water spurts out. A mandarin orange is a fruit grown mainly in Asia that peels easily with fingers. This fruit has been gaining in popularity in North America and Europe in recent years. The thickness of a mandarin orange peel is approximately 2 to $2.5 \mathrm{~mm}$. Therefore, its peel makes an ideal simulator for practicing the placement of purse-string sutures. We believe that young cardiovascular surgeons will benefit from this realistic simulation. This training method will help them reduce their anxiety during actual surgeries (Saito S, Okasaka T, Takeuchi E, Yamaguchi K, Koike A, Ueda Y. Convenient cannulation training method for aortic cannulation: gloves and peel method. Jpn J Thorac Cardiovasc Surg. 2004;52:545-547). Video available at: https://www.jtcvs.org/article/S0022-5223(20)33444-9/fulltext.

cardiopulmonary bypass, by reviewing video tapes of residents at various levels. However, we believe this approach is only an initial step toward establishing a technical assessment tool, and further standardized evaluation systems are necessary (Figure 5).

The second challenge includes establishing a systematic and well-organized off-the-job training curriculum. Because the number of cases for each resident is limited, the role of off-the-job training is substantial. Of note, young members of the JSCVS have developed useful self-training tools for learning appropriate knot tying (Video 1), accurate handling of needle holders (Video 2), and safe cannulation of the ascending aorta (Video 3). ${ }^{17}$ To validate their efforts, an efficient curriculum system and a standardized 
evaluation system with appropriate feedback must be established (Figure 5). ${ }^{18}$

The third challenge is that we currently do not have an efficient tool to measure the ability and quality of communication $^{20,21}$ among trainees and team members both inside and outside of operating rooms. ${ }^{18}$ Previous tools, such as the Non-Technical Skills for Surgeons system, ${ }^{22}$ are helpful and can be modified for assessment in cardiovascular surgery. Monitoring by video in the operating room and 360-degree evaluation by team members are possible, but these approaches require a high-level of commitment by the institution.

\section{CONCLUSIONS}

Cardiovascular surgery training in Japan has been evolving to achieve the highest quality training of our residents. The JBCVS provides a rigorous process involving regular in-house off-the-job training, lectures on basic and advanced cardiovascular surgery, and nontechnical skills training. The combined efforts of the JBCVS and the JCVSD are effective and vitally important in monitoring the quality of surgical training in each institution. Further efforts are required to standardize the quality assessment of both the technical and nontechnical skills of trainees.

\section{Conflict of Interest Statement}

The authors reported no conflicts of interest.

The Journal policy requires editors and reviewers to disclose conflicts of interest and to decline handling or reviewing manuscripts for which they may have a conflict of interest. The editors and reviewers of this article have no conflicts of interest.

The authors are grateful to Drs Akinobu Itoh and Masamichi Ono for providing the information of attending Japanese cardiovascular surgeons practicing abroad. The authors are most appreciative of Drs Shun Watanabe, Daisuke Yasumizu, and Shunei Saito for providing excellent videos of their original off-the-job training methods.

\section{References}

1. Kimoto S. Historical review of surgery of the heart and great vessels in Japan. $J$ Jpn Assoc Thorac Surg. 1975;23:341-59 (in Japanese).

2. Sakakibara S, Orihata H, Nakayama K, Ichii A, Saito H. First successful report of intracardiac repair of arterial septal defect under cardiac circulatory occlusion in the condition of artificial hibernation. Jap Med J. 1954;8:1598.

3. Horiuchi T, Koyamada K, Matano I, Mohri H, Komatsu T, Honda T, et al. Radical operation for ventricular septal defect in infancy. J Thorac Cardiovasc Surg. $1963 ; 46: 180$.
4. Hikasa Y, Shirotani H, Satomura K, Muraoka R, Abe K, Tsushimite K, et al. Open heart surgery in infants with an aid of hypothermic anesthesia. Arch Jpn Chir. 1967;36:495

5. Konno S, Imai Y, Iida Y, Nakajima M, Tatsuno K. New method for prosthetic valve replacement in congenital aortic stenosis associated with hypoplasia of the aortic valve ring. J Thorac Cardiovasc Surg. 1975;70: 909-17.

6. Sano S, Ishino K, Kawada M, Arai S, Kasahara S, Asai T, et al. Right ventricle to pulmonary artery shunt in first stage palliation of hypoplastic left heart syndrome. J Thorac Cardiovasc Surg. 2003:126:504-10.

7. Ueda Y, Miki S, Kusuhara K, Okita Y, Tahata T, Yamanaka K. Surgical treatment of aneurysm or dissection involving the ascending aorta and aortic arch utilizing circulatory arrest and retrograde cerebral perfusion. J Cardiovasc Surg (Torino). 1990;31:553-8.

8. Ministry of Internal Affairs and Communications. White paper information and communication in Japan from Ministry of Internal Affairs and Communications. Available at: https://www.soumu.go.jp/johotsusintokei/whitepaper/ja/h30/html/ nd101100.html. Accessed March 1, 2020.

9. Committee for Scientific Affairs, The Japanese Association for Thoracic Surgery, Shimizu H, Endo S, Natsugoe S, Doki Y, et al. Thoracic and Cardiovascular Surgery in Japan: Annual report by The Japanese Association for Thoracic Surgery. Gen Thorac Cardiovasc Surg. 2018;66:581-615.

10. Asano K. Thirty-year History of Japanese Association for Thoracic Surgery Published by Japanese Association for Thoracic Surgery; 1977 [in Japanese] Available at: http://www.jats-org/anniversary/30/index.html. Accessed January $28,2021$.

11. Nawata K, D'Agostino RS, Habib RH, Kumamaru H, Hirahara N, Miyata H, et al. First database comparison between the United States and Japan: coronary artery bypass grafting. Ann Thorac Surg. 2020;109:1159-64.

12. Brescia AA, Lou X, Louis C, Blitzer D, Coyan GN, Han J, et al. The thoracic surgery resident association: past contribution, current efforts, and future direction. J Thorac Cardiovasc Surg. August 31, 2020 [Epub ahead of print].

13. Noly PE, Rubens FD, Ouozunian M, Quantz M, Shao-Hua W, Pelletier M, et al Cardiovascular surgery training in Canada: current state and future perspectives. J Thorac Cardiovasc Surg. 2017;154:998-1005.

14. Zakkar M, Benedetto U, Angelini GD, Murphy G, Shah R, Jahangiri M, et al Cardiothoracic surgery training in the United Kingdom. J Thorac Cardiovasc Surg. 2019; 157:1948-55.

15. Shi WY, Oldfield Z, Tam R, Cochrane AD, Smith AS. Cardiothoracic surgery training in Australia and New Zealand. J Thorac Cardiovasc Surg. 2018;156: 718-25.

16. Mennander A, Gudbjartason T, Jeppsson A, Hjortdal V, Tønnessen T. Specialist training for cardiothoracic surgery in the Nordic countries. J Thorac Cardiovasc Surg. 2020;159:1002-8.

17. Endorsed by JBCVS. In: JATS, JSCVS, JSV, eds. Cardiovascular Surgery OffThe-Job Training Textbook. Tokyo, Japan: Nankodo; 2018.

18. Bando K. Development of standardized evaluation methods for off-the-job training. J Jpn Surg Soc. 2019;120:534-42.

19. Yamamoto H, Miyata Y, Tanemoto K, Saiki Y, Yokoyama H, Fukuchi E, et al. Quality improvement in cardiovascular surgery: results of a surgical quality improvement programme using a nationwide clinical database and databasedriven site visits in Japan. BMJ Qual Saf. 2020;29:560-8.

20. Sexton JB, Thomas EJ, Helmreich RL. Error, stress, and teamwork in medicine and aviation: cross sectional surveys. BMJ. 2000;320:745-9.

21. Roberts NK, Williams RG, Kim MJ, Dinnington GL. The briefing, intraoperative teaching, debriefing model for teaching in the operating room. J Am Coll Surg. 2009;208:299-303.

22. Yule S, Flin R, Paterson-Brown S, Maran N. Non-technical skills for surgeons in the operating room: a review of the literature. Surgery. 2006;139: $140-9$.

Key Words: cardiovascular surgery training, off-the-job training, on-the-job training, quality assessment 


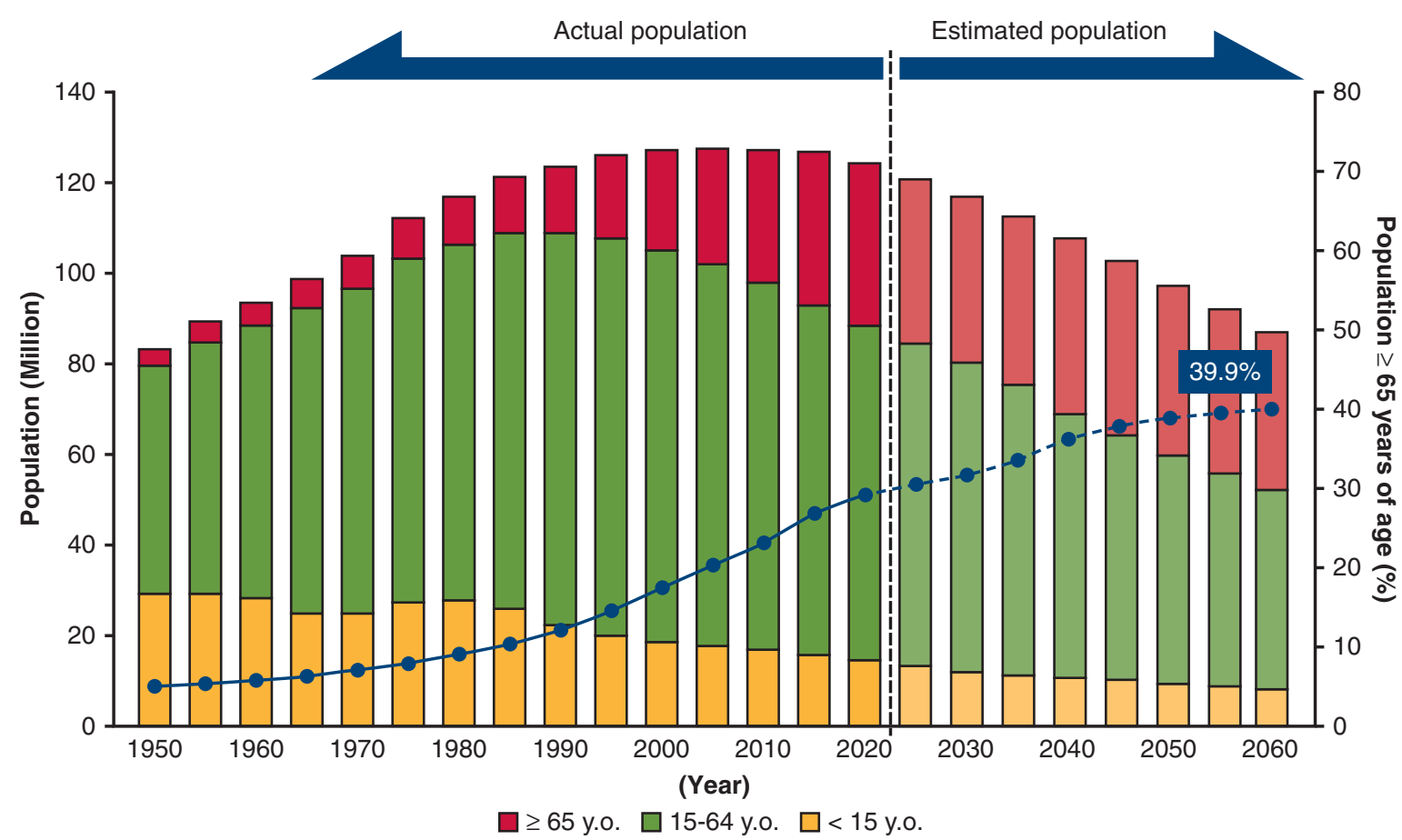

FIGURE E1. Trends of population in Japan. Heavy color bars indicate the actual population between 1950 and 2010; light color bars indicate estimated population up to 2060 in Japan. Estimated ratio of population aged 65 years or more is $39.9 \%$ in 2060 .

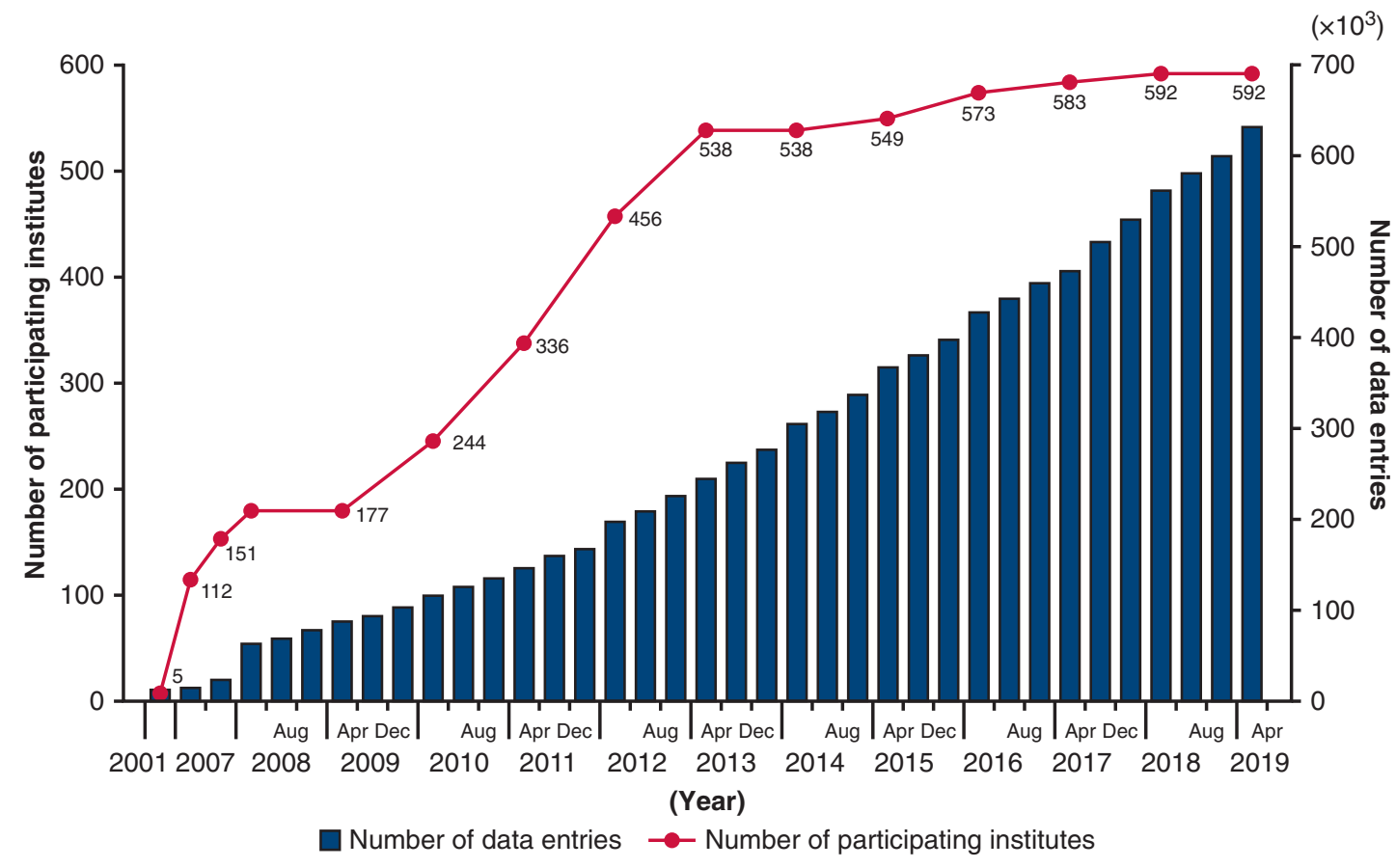

FIGURE E2. JCVSD data entries for adult patients. As of April 2019, the total number of entries was 632,975 cases, and the total number of participating institutions was 592 . 


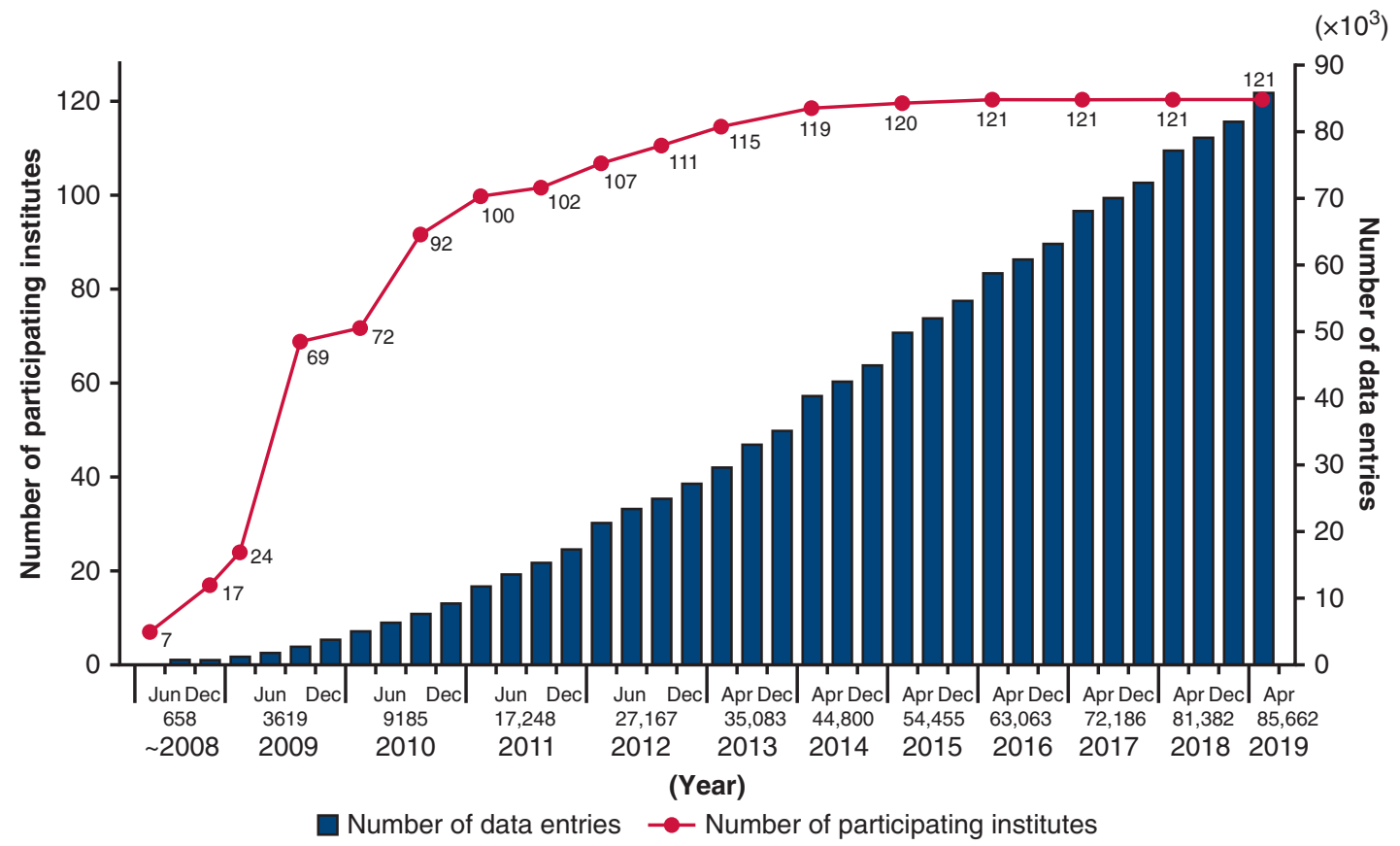

FIGURE E3. JCVSD data entries for patients with congenital heart disease. As of April 2019, the total number of entries was 85,662 cases and the total number of participating institutions was 121 . 
TABLE E1. Requirement for JBCVS-certified surgical educators

1. JBCVS-certified surgeon

2. (1) Completed first renewal of JBCVS board certification or

(2) International member of Asian Society of Cardiovascular and Thoracic Surgery

3. Operative experience 100 cases

(1) $>50$ cases is category B or C, 2) $>30$ cases is category C

5. Must have $\geq 5$ articles as a primary author in peer-reviewed journals

6. Approval of certificate by JBCVS board members

$J B C V S$, Japanese Board of Cardiovascular Surgery.
TABLE E2. Requirements for cardiovascular training program

A. Requirements for core cardiovascular training program

1. $>100$ cardiovascular cases/y (mean of past $3 \mathrm{y}$ )

2. (1) Cardiac and thoracic aortic surgery program

(a) At least $\geq 40$ cases in cardiac and thoracic aortic surgery

(2) Abdominal and peripheral vascular surgery major program

(a) At least $\geq 20$ abdominal aortic surgeries

(b) At least $\geq 20$ peripheral aortic surgeries

(c) At least $\geq 20$ venous surgeries

3. JBCVS-approved cardiovascular surgery training program

4. $\geq 1$ JBCVS-certified program director or consultant

5. Attendance of residents at official safety management program

6. $\geq 2$ Board-certified perfusionists

7. Cooperation for JBCVS quality-improvement program

B. Requirements for Satellite Cardiovascular Training Program

1. Recommendation of program director of core training program and approval of director of hospital

2. (1) Involvement of curriculum of core training program

(2) $\geq 50$ cases in the year leading up to application

3. (1) Cardiac and thoracic aortic surgery program

(a) At least $\geq 40$ annual cases in cardiac and thoracic aortic surgery

(2) Abdominal and peripheral vascular surgery major program

(a) At least $\geq 20$ annual abdominal aortic surgeries

(b) At least $\geq 20$ annual peripheral aortic surgeries

(c) At least $\geq 20$ annual venous surgeries

All the annual numbers are counted as the mean of the $3 y$ leading up to application

4. $\geq 1$ JBCVS-certified program director or consultant

5. Attendance of residents at official safety management program

6. $\geq 2$ board-certified perfusionists

7. Cooperation with JBCVS quality-improvement program 
TABLE E3. Detailed classification of operative procedures for the Japanese Board of Cardiovascular Surgery Certification

Degree of difficulty (A)

Degree of difficulty (B)

Degree of difficulty (C)

1. Surgeries for congenital heart diseases 1 . Surgeries for congenital heart diseases

(1) PDA surgery

(2) ASD closure surgery

(3) VSD (subpulmonary type) closure surgery

(4) Pulmonary valvotomy

2. Valvular surgeries

(1) Tricuspid valve repair

(2) Commissurotomy of atrioventricular valve

3. Other cardiac surgeries

Pericardial incision/pericardial window

(1) Procedure

(2) Pulmonary vein isolation

4. Arterial surgeries

(1) Thrombectomy

(2) Extra-anatomic bypass (lower limbs)

(3) Peripheral arterial aneurysm

(4) Percutaneous angioplasty

5. Venous surgery

(1) Venous thrombectomy

6. Other vascular surgeries

(1) Arteriovenous shunt creation

7. Other surgeries equivalent to those described

(2) Pulmonary artery banding

(3) CoA surgery closure venous return repair (partial type) ventricle

(10) Aortic valvotomy

(11) Surgery for coronary fistula

(12) Bidirectional Glenn procedure

2. Valvular surgeries

(1) Aortic valve replacement

(2) Mitral valve replacement

(3) Other single valve replacement transfemoral approach transapical approach

3. Surgery for ischemic heart disease
(1) Systemic-to pulmonary artery shunting

(4) VSD (perimembranous/muscular type)

(5) Surgery for partial anomalous pulmonary

(6) Surgery for atrioventricular septal defect

(7) Surgery for sinus of Valsalva aneurysm

(8) Surgery for double-chambered right

(9) Right ventricular outflow tract reconstruction

(4) Transcatheter aortic valve replacement-

(5) Transcatheter aortic valve replacement-

(1) $\mathrm{CABG}(\mathrm{x} 1)$

4. Other cardiac surgeries

(1) Removal of cardiac tumor

(2) Pericardiectomy (constrictive pericarditis)

(3) Maze procedure

5. Aortic surgeries

(1) Ascending aorta replacement

(2) Descending aorta replacement

(3) Abdominal aorta replacement

(4) Stent graft implantation without branch reconstruction

6. Arterial surgeries

(1) Revascularization (above knee)

(2) Revascularization (including subclavian artery) upper limbs

(3) Surgery for ruptured peripheral arterial aneurysm

7. Venous surgeries

(1) Revascularization for peripheral veins

Other vascular surgeries

(1) Vascular injury repair

(2) Thoracic outlet syndrome surgery

(3) Surgery for lymphedema

Other surgeries equivalent to those described above
1. Surgeries for congenital heart diseases

(1) Surgery for tetralogy of Fallot

(2) Surgery for transposition of the great arteries

(3) Surgery for double outlet right ventricle

(4) Surgery for total anomalous pulmonary venous return

(5) Surgery for atrioventricular septal defect (complete type)

(6) Fontan procedure

(7) Surgery for Ebstein's anomaly

(9) Norwood procedure

(10) Surgery for supravalvular/supravalvular aortic stenosis

(11) Surgery for coronary artery anomaly

(12) Surgery for the coarctation of the aorta (complex type)/interrupted aortic arch

(13) Reconstruction of peripheral pulmonary artery

(14) Ross procedure

2. Valvular surgeries

(1) Mitral valve repair

(2) Aortic valve repair

(3) Complex valve surgery

(4) Aortic annular enlargement procedure

(5) Aortic root reconstruction

3. Surgery for ischemic heart disease

(1) $\mathrm{CABG}(\geq 2)$

(2) Surgery for complications of myocardial infarction

4. Other cardiac surgeries

(1) Pulmonary artery thrombectomy

(2) Surgery for ventricular tachycardia

(3) Left ventriculoplasty

(4) Implantation of artificial heart

5. Aortic surgeries

(1) Aortic arch replacement

(2) Thoracoabdominal aorta replacement

(3) Abdominal aorta replacement with renal arteries clamped

(4) Surgery for aortic dissection

(5) Surgery for infection/inflammatory aortitis

(6) Surgery for ruptured aneurysm

(7) Surgery for atypical CoA

(8) Stent graft implantation with branch reconstruction

6. Arterial surgeries

(1) Revascularization (below knee)

(2) Carotid endarterectomy

(3) Reconstruction of vertebral artery

(4) Reconstruction of visceral artery (including renal arteries)

7. Venous surgeries

(1) Reconstruction of vena cava

Other surgeries equivalent to those described 
TABLE E4. Requirement for renewal of Japanese Board of Cardiovascular Surgery certification

JBCVS certified surgeons are required for renewal every $5 \mathrm{y}$.

1. Renewal candidates must be both JBS and JBCVS certified

2. Renewal candidates must be a member of at least 2 of JATS, JSCVS, and JSVS for the previous $5 \mathrm{y}$.

3. Renewal candidates must have at least 100 cases as a primary surgeon or teaching assistant for the previous $5 \mathrm{y}$. For renewal candidates for the first time, at least 50 cases should be category B or C.

4. Academic performance

(1) Renewal candidates have published at least 3 articles in peer-reviewed journals as primary or co-authors.

(2) Renewal candidates must have attended at least 5 times of JATS, JSCVS, or JSVS annual meetings.

(3) Renewal candidates must have attended at least 3 times of postgraduate course during JATS, JSCVS, or JSVS meetings.

(4) Renewal candidates must have attended at least 2 times of medical safety conferences during JATS, JSCVS, or JSVS meetings.

5. Renewal candidates are required to participate at least 1 surgical educator course.

JBCVS, Japanese Board of Cardiovascular Surgery; JBS, Japanese Board of Surgery; JATS, Japanese Association for Thoracic Surgery; JSVS, Japanese Society of Vascular Surgery. 